See discussions, stats, and author profiles for this publication at: https://www.researchgate.net/publication/326293084

\title{
A 3D tomographic investigation to elucidate the low-velocity impact resistance, tolerance and damage sequence of thin non-crimp fabric laminates: effect of ply-thickness
}

Preprint · July 2018

DOl: 10.1016/j.compositesa.2018.07.013

CITATIONS

0

5 authors, including:

Santiago García Rodríguez

Universitat de Girona

11 PUBLICATIONS 6 CITATIONS

SEE PROFILE

Anton Bardera

Universitat de Girona

45 PUBLICATIONS 706 CITATIONS

SEE PROFILE

Some of the authors of this publication are also working on these related projects:

COST FAIM View project

Use of light non-woven veils to enhance the damage tolerance of thin laminates made with thin-ply non-crimp fabrics View project
READS

150

Josep Costa

Universitat de Girona

141 PUBLICATIONS 3,280 CITATIONS

SEE PROFILE

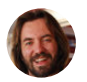

Daniel Trias

34 PUBLICATIONS 511 CITATIONS

SEE PROFILE
Universitat de Girona 


\title{
A 3D tomographic investigation to elucidate the low-velocity impact resistance, tolerance and damage sequence of thin non-crimp fabric laminates: effect of ply-thickness
}

\author{
S.M. García-Rodríguez ${ }^{\mathrm{a}, *}$, J. Costa $^{\mathrm{a}}$, A. Bardera ${ }^{\mathrm{b}}$, V. Singery ${ }^{\mathrm{c}}$, D. Trias ${ }^{\mathrm{a}}$ \\ ${ }^{a}$ AMADE, Polytechnic School, University of Girona, Av. Universitat de Girona, 4. 17003 Girona, \\ Spain \\ ${ }^{b}$ Graphics and Imaging Laboratory, University of Girona, Av. Universitat de Girona, 4. 17003 \\ Girona, Spain \\ ${ }^{c}$ Chomarat, 39 Avenue de Chabannes, 07160, Le Cheylard, France
}

\begin{abstract}
While thin-plies delay the onset of matrix cracking and improve certain in-plane mechanical properties, the effect they have on the out-of-plane response remains unclear. We compared the impact resistance, tolerance and sequence of failure events of thin laminates manufactured with thin- or standard-ply non-crimp fabrics (fibre areal weight of 67 and 134 gsm per ply). Damage initiation and propagation was detailed using (a) quasi-static indentation and impact tests at incremental energy levels and (b) X-ray tomography. The analysis revealed the damage mechanisms underlying the observed load drops in the force-displacement curves. In the indented specimens, the 3D post-process ascribed matrix cracks and delaminations to their corresponding plies/interfaces. Standard-ply samples develop more extended delaminations and delay fibre failure, improving the load-carrying capacity and increasing compression after impact (CAI) strength by $27 \%$ for impact at $14 \mathrm{~J}$. Keywords: Thin-ply, B. Impact behaviour, C. Damage mechanics, D. CT analysis
\end{abstract}

\footnotetext{
*Corresponding author. Tel.: +34972 418817

Email addresses: santiago.garcia@udg.edu (S.M. García-Rodríguez), josep.costa@udg.edu (J. Costa)
} 


\section{Introduction}

Impact damage is a major concern in composite laminates as it may impair the mechanical properties of components and is difficult to detect. In service, low energy strikes may generate matrix cracks and delaminations that deteriorate structural integrity [1-3]. In an attempt to reduce weight and costs, the airline industry aims to manufacture increasingly thinner fuselage and wing skins using out-of-autoclave methods which, in turn, accentuate impact susceptibility [4].

Thin-plies are attracting growing interest as they delay matrix cracking and associated delamination, as well as increase certain in-plane mechanical properties [5-10]. Their main advantage comes from the in-situ strength [11-13], however, confining a higher number of plies within the same thickness may also increase the stiffness because of pure structural effects [14]. During impact, damage tolerance may be improved in the thin-plies (Table 1).

[Table 1 about here.]

Yokozeki et al. [15] examined the out-of-plane damage sequence of carbon/toughened epoxy $\left(45^{\circ} / 0^{\circ} /-45^{\circ} / 90^{\circ}\right)_{n s}$ laminates with $2.2 \mathrm{~mm}$ nominal thickness. They considered ply-thicknesses of $75 \mu \mathrm{m}$ (thin, $n=4$ ) and $145 \mu \mathrm{m}$ (standard, $n=2$ ). The thin-ply layup presented reduced delamination propagation and premature fibre failure when compared to its standard-ply counterpart. Wagih et al. [16] performed quasi-static indentation tests at incremental deflection levels in $\left[\left(\left(45^{\circ} /-45^{\circ}\right) /\left(0^{\circ} / 90^{\circ}\right)\right)_{n}\right]_{s}$ plain weave fabric laminates with $4.5 \mathrm{~mm}$ nominal thickness. They observed that decreasing the yarn thickness from $80 \mu \mathrm{m}$ (thin, $n=7$ ) to $40 \mu \mathrm{m}$ (ultra-thin, $n=14$ ) also resulted in premature fibre breakage. In both cases, the characterization was limited to $2 \mathrm{D}$ inspection and damage tolerance was not assessed.

The objective of this investigation is to (a) understand the impact failure mechanisms and damage sequence of thin carbon/epoxy laminates manufactured with 
thin- or standard-ply non-crimp fabrics (NCFs) and (b) justify their damage resistance and tolerance based on the observations in (a). We considered "thin" laminates (i.e. approximately $2.2 \mathrm{~mm}$ thick, thinner than those recommended by the standard ASTM D7137 [17]) to comply with the demands of the aircraft industry. We devised a low-velocity impact, quasi-static indentation (QSI), standard compression and compression after impact (CAI) test campaign, where damage induced by impact and QSI was inspected using ultrasonic C-scan and X-ray micro-computed tomography $(\mu \mathrm{CT})$. The latter provided ply-by-ply information as to how matrix cracks, delamination and fibre breakage evolve during out-of-plane events.

\section{Materials and Methods}

\subsection{Materials}

We used Chomarat's T700 GC carbon bi-axial NCFs, commercially known as C-PLY ${ }^{T M}$. In particular, $\left(0^{\circ} / 45^{\circ}\right)$ and $\left(0^{\circ} /-45^{\circ}\right)$ blankets of 134 and $268 \mathrm{~g} / \mathrm{m}^{2}$ fibre areal weight were considered, corresponding to a fibre areal weight of 67 and 134 gsm per unidirectional ply. NCFs reduce labour costs because they allow several layers to be laid in one-axis, which is ideal for handling plies of reduced thickness [18]. Two types of quasi-isotropic $\left[\left(45^{\circ} / 0^{\circ}\right) /\left(-45^{\circ} / 90^{\circ}\right)\right]_{n s}$ layups were designed by, if necessary, flipping over and/or rotating the fabrics: one with the thinner plies ( $n=4$, LTHIN), and the other with the thicker plies $(n=2$, LTHICK). They were manufactured by resin transfer moulding using HexFlowß RTM6 epoxy resin (for details of the process refer to a recent study by the authors [19]). The average thickness values of LTHIN and LTHICK tested specimens were $2.29 \pm 0.16$ and $2.17 \pm 0.05 \mathrm{~mm}$, where \pm means standard deviation. Their average fibre volume fractions were $54.81 \pm 1.97$ and $55.21 \pm 0.82 \%$, respectively (five samples per laminate were measured following the standard EN 2564:1998 [20]; for the same type of material, specimens with a higher thickness presented the lowest fibre volume fraction values). 


\subsection{Experimental tests}

Impact tests were carried out in a CEAST Fractovis Plus 7536 drop-weight tower with a $16 \mathrm{~mm}$ diameter hemispherical indenter. 100 x $150 \mathrm{~mm}$ specimens were positioned over a rectangular cut-out and held in place using four rubber-tipped clamps. For further insight into the impact set-up refer to González et al. [2]. The data provided by the drop-weight tower were the impactor force (the latter was instrumented with a load cell) and velocity just before the impact (measured with an optical sensor). This data was used to integrate the displacement and velocity of the impactor during the test, as well as the energy absorbed by the coupons as a function of time [1]. The energy dissipated by each sample was computed by subtracting the energy returned to the impactor (i.e. the elastic energy) to the maximum energy (in all cases within $\pm 0.2 \mathrm{~J}$ of the target energy). The sampling rate was $1000 \mathrm{kHz}$. QSI experiments utilised the same base plate, indenter geometry and clamping devices in order to achieve boundary conditions comparable to those of the impact test (the purpose was to imitate the chronology of damage events taking place during impact [21-24]). QSI was conducted in an electromechanical MTS INSIGHT囚100 testing machine with a $100 \mathrm{kN}$ load cell. The cross-head displacement rate was $0.5 \mathrm{~mm} / \mathrm{min}$ to avoid dynamic effects [22, 23]. The energy applied to the system was calculated by integrating the area under the load-displacement curve.

Compression tests were performed using an electromechanical MTS INSIGHT®100 testing machine with a $100 \mathrm{kN}$ load cell. The aim was to quantify the pristine compressive strength of LTHIN and LTHICK. 12.7 x $140 \mathrm{~mm}$ specimens were tested using a compression fixture in accordance with the standard ASTM D6641/D6641M-14 [25]. The cross-head displacement rate was $1.3 \mathrm{~mm} / \mathrm{min}$. The ultimate compression strength was calculated by dividing the maximum load to failure by the specimen's cross-section measured at the gage region.

CAI tests were conducted using an electromechanical MTS INSIGHTß300 testing machine with a $300 \mathrm{kN}$ load cell. A non-standard CAI device adopted from Remacha et al. [26] was used. This fixture enabled the testing of laminates thinner than those 
recommended by the standard ASTM D7137/D7137M [17], which would otherwise fail by global buckling [26-28]. The device consisted of two antibuckling plates with three vertical ribs that stabilize the specimen during the test. The central rib includes a $52 \times 42 \mathrm{~mm}$ central cut-out to avoid any interference with the damaged zone. The cross-head displacement rate was $0.5 \mathrm{~mm} / \mathrm{min}$.

Impact energies were selected to ensure that a considerable amount of damage (i.e. observation of fibre failure in the non-impacted surface of the specimens) developed in LTHIN (10 J) and LTHICK (14 J). The QSI experimental campaign was divided into four deflection levels, where deflection means the displacement of the indenter during the test $[22,23]$. The higher deflection $(\mathrm{d}=5.24 \mathrm{~mm})$ corresponds to the load drop developed in LTHIN. The smaller deflections $(\mathrm{d}=3 \mathrm{~mm}, \mathrm{~d}=4 \mathrm{~mm}$ and $\mathrm{d}=4.4 \mathrm{~mm})$ were chosen based on the onset of acoustic emissions heard during the testing of both types of laminate. These deflections resulted in applied energies of approximately 2.5, 4, 5.5 and $8 \mathrm{~J}$. Three samples of each laminate were impacted at $10 \mathrm{~J}$, and at least four at $14 \mathrm{~J}$, all of which were eventually tested under CAI. In addition, one specimen per layup was indented to each of the deflections above. The combination of QSI and impact experiments provided information about damage resistance and the sequence of failure events, while the CAI tests gave insight into damage tolerance. Finally, six LTHIN and seven LTHICK samples were tested under pure compression. The entire campaign was performed at $23 \pm 2{ }^{\circ} \mathrm{C}$ and $50 \pm 5 \%$ humidity in the mechanical testing laboratory at the University of Girona. The laboratory is ISO17025 and NADCAP (non-metallic materials) accredited.

\subsection{Damage inspection and $3 D$ post-process}

All the indented and impacted coupons were inspected by C-scan ultrasonic technique using an OLYMPUS OMNI MX system automatized with a robotic arm. In addition, every indented specimen and representative impacted samples were inspected by $\mu \mathrm{CT}$ (for details about both the $\mathrm{C}$-scan and $\mu \mathrm{CT}$ inspection equipments

refer to [19]). During the tomography scans, the use of contrast agents was avoided to 
observe matrix cracks and delaminations regardless of their interconnection.

In the indented specimens, the entire damage scenario was observed as decided from a previous C-scan. Prior to inspection, the samples were cut into approximately $10 \mathrm{~mm}$ width coupons to minimize undesired X-ray absorption perpendicular to the axis of rotation [29]. The scanning parameters were $55 \mathrm{kV}, 80 \mu \mathrm{A}, 1.5 \mathrm{~s}$ exposure time, 1400 projections (3 integrations/projection) and 5-5.5 $\mu \mathrm{m}$ pixel size, corresponding to a field of view of $11.2-12.32 \mathrm{~mm}$. In the impacted specimens, only a representative region centred at the impact site was captured. The inspection parameters were $70 \mathrm{kV}, 75 \mu \mathrm{A}, 2.5 \mathrm{~s}$ exposure time, 1400 projections (3 integrations/projection) and 6.5 or $10 \mu \mathrm{m}$ pixel size for 10 and $14 \mathrm{~J}$ impact energy (fields of view of 14.6 and $22.4 \mathrm{~mm}$, respectively).

To provide a comprehensive 3D analysis of the damage scenario developed within indented specimens, the $\mu \mathrm{CT}$ slices were post-processed using Matlab:

1. each sample was sliced into one-pixel-thick planes perpendicular to the thickness direction. A 2D median filter was applied to each of the planes. The objective was to remove image noise while preventing information losses at the planes where delamination occurs (i.e. no pixels were filtered through-the-thickness),

2. to separate the specimen from the background, a mask was obtained using greylevel thresholding and morphological operators,

3. damage was segmented by setting a user-defined grey value threshold (because of their narrow crack opening, the smaller cracks developed in the thin-ply samples were difficult to segment or post-process),

4. after the segmentation process, the $\mu \mathrm{CT}$ slices presenting image artifacts (i.e. zones with excessive noise or ring artifacts) were cleaned using morphological operators. Then, a more refined manual cleaning was performed slice-by-slice using an in-house routine,

5. each segmented pixel (corresponding to damage developed in the sample) was labelled according to its distance from the indented surface. The purpose was to 
ascribe the damage to particular plies or interfaces. The former coordinate system was selected to take into account the specimen's curvature after indentation [30], i.e. pixels lying in the same ply/interface have approximately the same scalar value,

6. images were rendered in 3D using the software Starviewer [31]. Matrix cracks were coloured in black, and delaminations coloured based on their interface position (Starviewer software allows pixel scalar values to be coloured using a transfer function).

\section{Results}

Figures 1a-b present the load-displacement curves of representative LTHIN and LTHICK specimens impacted at 10 and $14 \mathrm{~J}$. In the thin-ply laminate, the load grew non-linearly until a local maximum $\left(F_{i}\right)$, followed by a load drop and a decrease in the bending stiffness. In contrast, the LTHICK samples only presented such a local maximum for impact at $14 \mathrm{~J}$, which occurred at a higher force than in LTHIN. Table 2 summarizes the value of $F_{i}$ and the magnitude of the associated load drop for each material system/impact energy.

[Table 2 about here.]

[Figure 1 about here.]

Figures 1c-d compare the QSI and impact load-displacement curves of each layup. In both systems, the curve of the coupon indented at $\mathrm{d}=5.24 \mathrm{~mm}$ overlapped the ones subjected to lower deflections except for the standard-ply sample indented at $\mathrm{d}=$ $3 \mathrm{~mm}$, which came from a different panel (with a slightly different volume fraction) than the rest of the specimens from the same batch. In the LTHIN sample indented at the highest deflection (applied energy of approximately $8 \mathrm{~J}$ ), a local maximum force preceded several consecutive load-drops (see $F_{q}$ at approximately $3.3 \mathrm{kN}$ ). In contrast, the LTHICK counterpart presented a non-linear response without concomitant load 
oscillations. Finally, in both materials, the impacted specimens displayed a higher stiffness than the QSI ones owing to the dynamic components of the former test (as observed elsewhere [24]).

When an impact load bends a composite plate, part of the energy bounces back as elastic energy and part of it dissipates in the form of damage. We monitored the maximum force supported (i.e. the maximum load value measured during the experiment) and the energy dissipated by the LTHIN and LTHICK specimens (Figure 2). At both impact energies, LTHIN supported a lower maximum force and dissipated a higher amount of energy than LTHICK.

[Figure 2 about here.]

Figure 3 plots the C-scan projected damage area against the energy applied during QSI and impact tests. In LTHICK, the damage grew almost linearly with the energy applied during both types of experiment. On the other hand, the LTHIN coupons exhibited very reduced damage until $8.2 \mathrm{~J}$, from which the damage started to grow faster than in the thick-ply system. This tendency agrees well with the results in Figure 2, i.e. decreased damage area after impact increases the load-carrying capacity and lessens the energy dissipated though damage propagation.

[Figure 3 about here.]

Figures 4-8 summarize the damage sequence of LTHIN and LTHICK. We omitted the coupons indented at $\mathrm{d}=4.4 \mathrm{~mm}$ as they did not present any new damage forms relative to those indented at the previous deflection step. In addition, Appendix A details the damage mechanisms developed in each ply/interface of the LTHIN and LTHICK specimens indented at $\mathrm{d}=3$ and $\mathrm{d}=4 \mathrm{~mm}$, i.e. it compares how damage initiates in both types of laminate (NB: the thin-ply specimen indented at $\mathrm{d}=3 \mathrm{~mm}$ displayed no significant damage and therefore is not considered in the Appendix).

[Figure 4 about here.] 
[Figure 5 about here.]

The $\mu$ CT slices evidenced that LTHIN and LTHICK presented resin-rich areas (commonly called "resin pockets") dispersed through-the-volume of the laminate. The higher the ply-thickness, the greater the size of the resin pockets (Figures $4 \mathrm{a}$ and 5b).

The LTHIN specimen indented at $\mathrm{d}=3 \mathrm{~mm}$ featured no damage except for scarce matrix cracks in the bottom part of the laminate (Figure 4a) - the top and bottom surfaces will be henceforth defined as the ones lying closest to and farthest from the impactor. In contrast, the standard-ply coupon developed matrix cracks in the seven bottommost plies and one delamination in the first $0^{\circ} / 45^{\circ}$ interface located under the mid-plane (Figures 5a and 6b, the delamination is indicated as (i) in Figure 5a). We discerned two types of intralaminar cracks, (ii) in Figure 5a these are the $90^{\circ}$ cracks caused by tensile stresses in the rear part of the laminate ("tensile cracks" [23]), and (iii) in Figure 5a these are the $45^{\circ}$ cracks induced by shear stresses in the inner part of the laminate ("shear cracks" [22]). Besides this, we observed matrix cracks initiating in resin pockets (see, for example, the first $-45^{\circ}$ ply located under the mid-plane of the LTHIN specimen indented at $\mathrm{d}=4 \mathrm{~mm}$, Figure A.2 in Appendix A).

[Figure 6 about here.]

In the thin-ply material, QSI damage initiated at $4 \mathrm{~mm}$ deflection (applied energy of approximately $4 \mathrm{~J}$, Figures $4 \mathrm{~b}, 6 \mathrm{c}$ and $7 \mathrm{a}$ ). It localized in the bottom-half of the laminate, where we observed tensile/shear cracks and delamination in the three $0^{\circ} / 45^{\circ}$ interfaces under the mid-plane (Figure $4 \mathrm{~b}$ ). Another delamination developed through a resin-rich area located below the $90^{\circ}$ ply-cluster (see the green delamination in Figures $6 \mathrm{c}$ and $7 \mathrm{a}$ ), where the shear stress distribution is close to maximum. In the LTHICK sample indented at $\mathrm{d}=4 \mathrm{~mm}$, damage extended to the bottom three-quarters of the plate (Figures $5 \mathrm{~b}$ and $7 \mathrm{~b}$ ). In this region, matrix cracks developed within each ply (see Figure A.3 in Appendix A) and allowed delamination to concatenate resulting in a symmetric "spiral stair-case" profile [23] (Figure 7b). At 
least one pair of matrix cracks with dissimilar orientation confined delamination propagation (Figure 6d), whereas we observed multiple micro-cracks parallel to the "main" cracks [32] ((iv) in Figures 5b and 6b).

[Figure 7 about here.]

The LTHIN specimen indented at $\mathrm{d}=5.24 \mathrm{~mm}$ (applied energy of approximately 8 $\mathrm{J})$ presented fibre failure in almost all the plies in the lower half of the laminate (Figures 4c and 8a). In addition, matrix cracks and delaminations 1-3 mm wide extended from the bottom to the top parts of the plate except for the five interfaces closest to the indenter where fibre crushing occurred because of high compressive stresses (Figure 8a). In the LTHICK sample indented at $\mathrm{d}=5.24 \mathrm{~mm}$, delaminations developed in the same interfaces as in the coupon indented at $\mathrm{d}=4 \mathrm{~mm}$ (Figures 7-8b), albeit with higher lateral extension (Figures 6d and f). Additionally, we observed that the delamination in the bottommost $-45^{\circ} / 0^{\circ}$ interface migrated to the adjacent $0^{\circ} / 45^{\circ}$ favoured by a transverse crack developed within a resin pocket (Figure 8c).

[Figure 8 about here.]

Once fibre breakage initiated in the LTHIN system (Figure 4c), it extended through-the-thickness of the laminate (Figure 4d) and induced further delamination propagation (Figure 4e). The LTHICK specimens presented fibre breakage solely after impact at $14 \mathrm{~J}$ (Figure 5e).

Figure 9 introduces the compressive strength of pristine and impacted LTHIN and LTHICK coupons. Each standard compression specimen failed within the gage section. The failure mode was either "brooming" (LTHIN) or a combination of brooming and delamination (LTHICK). In the CAI experiments, all the samples failed by local buckling at the impact site followed by damage propagation perpendicular to the applied load. Despite the scatter presented by coupons of the same batch, LTHIN improved the standard compressive strength by approximately $3 \%$ compared to the 
thick-ply baseline, typically attributed to the more homogeneous microstructure (i.e. in the case of NCFs, to the reduced size of the resin pockets) or the improved fibre dispersion inherent to the thinner plies $[6,7]$. On the other hand, LTHIN decreased the CAI strength by $27 \%$ for impact at $14 \mathrm{~J}$.

[Figure 9 about here.]

\section{Discussion}

The microstructure of NCF laminates presents resin accumulations because the stitching yarns deviate carbon tows from their uniform directions, generating multiple and regularly spaced fibre-free regions [33]. The higher the ply-thickness, the bigger the length of and the distortion induced by the NCF stitches (Figures $4 \mathrm{a}$ and 5b). We observed that resin pockets favoured the initiation of matrix cracks (e.g. see the first $-45^{\circ}$ ply below the mid-plane of the LTHIN specimen indented at $\mathrm{d}=4 \mathrm{~mm}$, Figure A.2) and interacted with the propagation of delaminations (Figure 8c), which seems obvious as pure epoxy has less resistance than the carbon-epoxy composite.

The load-displacement curves of LTHIN and LTHICK exhibited one or several consecutive load drops during impact and/or QSI experiments $\left(F_{i}\right.$ and $F_{q}$ in Figure 1$)$. According to our $\mu \mathrm{CT}$ observations, such load drops correspond to the development of fibre failure localized in the bottom half of the laminate (Figures 5e and 4c). On the other hand, the LTHICK specimens exhibited extended delamination propagation without associated evidence in the load-displacement curve (Figures 1d and 5a-d). This arises from the thickness-to-length ratio of the coupons. For small ratios (e.g. thin laminates), bending deflection and non-linear membrane stiffening effects dominate over shear; which may obscure the evidence of delamination onset in the force-displacement curve $[21,34]$. In contrast, the curve of thick laminates typically displays a load drop corresponding to the initiation of delamination [16, 23, 24].

The sequence of damage events developed in thin- and standard-ply materials displays common qualitative trends. First, tensile and shear cracks develop in the 
bottom part of the laminate, accompanied by a delamination in the $0^{\circ} / 45^{\circ}$ interface (LTHICK) or in the three $0^{\circ} / 45^{\circ}$ interfaces (LTHIN) under the mid-plane (Figures 4b and 5a). Then, shear cracks extend from the bottom to the top and allow delaminations to concatenate through-the-thickness [23] (Figures 4c, 5b, 7b and 8a, NB: the exception to this are the 4-5 interfaces under the impactor, where high compressive stresses inhibit delamination propagation). Finally, fibre failure develops in the rear part of the laminate; subsequently evolving towards the top and inducing further damage propagation (Figures 4c-e and 5e). The fact that matrix cracks, delaminations and fibre failure grow bottom-to-top is, again, a consequence of the low thickness (and associated high deflections) of the plate [35]. We observed that a pair of long matrix cracks confined delamination (Figure 6d). Besides, multiple "micro-cracks" parallel to the long cracks developed along with delamination propagation (e.g. (iv) in Figure 5b) [32, 36]. The latter could derive from stress redistributions near the main matrix cracks [37], suggesting that delamination may grow progressively (confined between the smaller cracks) rather than in a single-step process.

The difference between LTHIN and LTHICK is the magnitude of the various damage mechanisms and the energy at which they occur. LTHIN displays smaller matrix cracks/delaminations that appear at higher QSI deflections (or energy levels) than those developed in LTHICK (Figure 6a-d), attributed to the improved in-situ strength in transverse tension and shear [11-13]. When tensile stresses due to bending overcome the tensile strength of the fibres, catastrophic fibre failure occurs [15] (Figure 4c). In contrast, LTHICK dissipates a higher fraction of the applied energy through delamination propagation, delaying the development of fibre breakage to the highest impact energy (Figure 5). This results in higher load-carrying capacity (Figure 2) and enhanced CAI strength for impact at $14 \mathrm{~J}$ (Figure 9). Our findings coincide with the results of Amacher et al. [7], who observed increased back-face fibre breakage as the laminate's ply-thickness decreased (they impacted coupons of relatively low thickness-to-length ratio). 
It is evident that the thin-ply laminate delays the initiation of matrix cracks and delaminations when compared to the standard-ply counterpart. However, these damage modes do not entail a decrease in bending stiffness in the load-displacement curve. In this regard, the standard-ply material displays a greater damage resistance: the load drop (and concomitant stiffness reduction) appears at higher applied energy. Selecting the optimal configuration would depend on the requirements of the structural application. If damage detectability prevails over load-carrying capacity, thin-plies should be used (according to our observations, LTHIN will probably suffer an earlier penetration than LTHICK, which can be detected with the naked eye, Figures 4-5e). The authors speculate that an optimal balance between damage suppression and CAI strength could be achieved by mixing thin- and standard-plies within the same laminate.

\section{Conclusions}

Combining quasi-static indentation and impact tests at incremental energy levels with 3D X-ray tomography, we compared the impact resistance, tolerance and sequence of failure events of thin laminates manufactured with thin- or standard-ply non-crimp fabrics. During the experiments we monitored the force-displacement data to associate load drops with observed damage mechanisms.

The load-displacement curve for both types of material presents a load drop corresponding to the development of fibre breakage localized in the bottom part of the laminate. Prior to the drop, matrix cracks and delaminations propagate with no associated evidence in the load-displacement curve. This is related to the low thickness-to-length ratio of the coupons, whereby bending and non-linear membrane stiffening effects dominate over shear.

The sequence of damage mechanisms developed in thin- and standard-ply laminates presents common qualitative trends (i.e., matrix cracks/delaminations extend from the bottom to the top of the laminate until fibre failure localizes in the rear part in

the coupons, which subsequently evolves towards the top and induces further damage 
propagation). However, the thin-plies delay the onset and reduce the extension of matrix cracks and delaminations. Lessening the energy dissipated through delamination propagation results in premature fibre breakage, decreased load-carrying capacity (by $25 \%$ and $55 \%$ for impact at 10 and $14 \mathrm{~J}$ ) and lower CAI strength for impact at $14 \mathrm{~J}$ (by $27 \%$ ).

As a last remark, the impact and QSI tests display a good coherence in terms of the

force local maxima $\left(F_{i}\right.$ and $\left.F_{q}\right)$, the projected damage area (which grows linearly with the incremental energy applied in both types of test) and the observed damage sequence. Therefore, for the type of material and range of energies considered in this study, the quasi-static test can be used to infer qualitative information about the damage mechanisms taking place during low-velocity impact.

\section{Acknowledgements}

The authors thank Chomarat (Le Cheylard, France) for manufacturing the materials used in this study. They would also like to acknowledge the support from the FEDER-UE and the Spanish government through the Ministerio de Economía y Competitividad, contract MAT2015-69491-C3-1-R. Thanks to the Graphics and Imaging Laboratory of the University of Girona for providing the software (Starviewer) and the support necessary to post-process and 3D render the tomographic slices. The first author is particularly grateful for the support received from the Secretaria d'Universitats i Recerca del Departament d'Empresa i Coneixement de la Generalitat de Catalunya through the pre-doctoral grant 2016FI_B_00551, co-funded by the Fondo Social Europeo (FSE).

\section{Appendix A Ply-by-ply damage analysis}

[Figure 10 about here.]

[Figure 11 about here.]

[Figure 12 about here.] 


\section{References}

[1] E. González, P. Maimí, P. P. Camanho, C. S. Lopes, N. Blanco, Effects of ply clustering in laminated composite plates under low-velocity impact loading, Composites Science and Technology 71 (6) (2011) 805-817.

doi:10.1016/j.compscitech.2010.12.018.

[2] E. González, P. Maimí, J. R. Sainz de Aja, P. Cruz, P. P. Camanho, Effects of interply hybridization on the damage resistance and tolerance of composite laminates, Composite Structures 108 (1) (2014) 319-331. doi:10.1016/j.compstruct.2013.09.037.

[3] Y. Liv, G. Guillamet, J. Costa, E. González, L. Marín, J. Mayugo, Experimental study into compression after impact strength of laminates with conventional and nonconventional ply orientations, Composites Part B: Engineering 126 (2017) 133-142. doi:10.1016/j.compositesb.2017.05.074.

[4] N. H. Nash, T. M. Young, P. T. McGrail, W. F. Stanley, Inclusion of a thermoplastic phase to improve impact and post-impact performances of carbon fibre reinforced thermosetting composites - A review, Materials and Design 85 (2015) 582-597. doi:10.1016/j.matdes.2015.07.001.

[5] S. Sihn, R. Kim, K. Kawabe, S. Tsai, Experimental studies of thin-ply laminated composites, Composites Science and Technology 67 (6) (2007) 996-1008. doi:10.1016/j.compscitech.2006.06.008.

[6] T. Yokozeki, Y. Aoki, T. Ogasawara, Experimental characterization of strength and damage resistance properties of thin-ply carbon fiber/toughened epoxy laminates, Composite Structures 82 (3) (2008) 382-389.

doi:10.1016/j.compstruct.2007.01.015.

[7] R. Amacher, J. Cugnoni, J. Botsis, L. Sorensen, W. Smith, C. Dransfeld, Thin ply composites: Experimental characterization and modeling of size-effects, 
Composites Science and Technology 101 (2014) 121-132.

doi:10.1016/j.compscitech.2014.06.027.

[8] G. Guillamet, A. Turon, J. Costa, J. Renart, P. Linde, J. A. Mayugo, Damage occurrence at edges of non-crimp-fabric thin-ply laminates under off-axis uniaxial loading, Composites Science and Technology 98 (2014) 44-50.

doi:10.1016/j.compscitech.2014.04.014.

[9] H. Yu-Chien, H. Sasayama, J. Yanagimoto, Mechanical properties and drawing process of multilayer carbon-fiber-reinforced plastic sheets with various prepreg thicknesses, Advances in Mechanical Engineering 9 (3) (2017) 1-12. doi:10.1177/1687814017692695.

[10] Y. Kim, S. Ko, W. Lay, T. Jingmeng, P. Chang, S. Thielk, Effects of Shallow Biangle, Thin-Ply Laminates on Structural Performance of Composite Wings, AIAA Journal 55 (6) (2017) 2086-2092. doi:10.2514/1. J055465.

[11] G. J. Dvorak, N. Laws, Analysis of Progressive Matrix Cracking In Composite Laminates II. First Ply Failure, Journal of Composite Materials 21 (April 1987) (1987) 309-329. doi:10.1177/002199838702100402.

[12] A. Arteiro, G. Catalanotti, A. R. Melro, P. Linde, P. P. Camanho, Micro-mechanical analysis of the in situ effect in polymer composite laminates, Composite Structures 116 (1) (2014) 827-840.

doi:10.1016/j.compstruct.2014.06.014.

[13] A. Arteiro, G. Catalanotti, A. R. Melro, P. Linde, P. P. Camanho, Micro-mechanical analysis of the effect of ply thickness on the transverse compressive strength of polymer composites, Composites Part A: Applied Science and Manufacturing 79 (2015) 127-137. doi:10.1016/j. compositesa.2015.09.015. 
[14] J. Zghal, A. Ammar, F. Chinesta, C. Binetruy, E. Abisset-Chavanne, High-resolution elastic analysis of thin-ply composite laminates, Composite Structures 172 (2017) 15-21. doi:10.1016/j.compstruct.2017.03.083.

[15] T. Yokozeki, A. Kuroda, A. Yoshimura, T. Ogasawara, T. Aoki, Damage characterization in thin-ply composite laminates under out-of-plane transverse loadings, Composite Structures 93 (1) (2010) 49-57. doi:10.1016/j.compstruct. 2010.06.016.

[16] A. Wagih, P. Maimí, E. González, N. Blanco, J. Sainz de Aja, F. de la Escalera, R. Olsson, E. Alvarez, Damage sequence in thin-ply composite laminates under out-of-plane loading, Composites Part A: Applied Science and Manufacturing 87 (2016) 66-77. doi:10.1016/j.compositesa.2016.04.010.

[17] ASTM Standard D7137/D7137M-12, Standard Test Method for Compressive Residual Strength Properties of Damaged Polymer Matrix Composite Plates. ASTM International, West Conshohocken, PA (2012). URL: www.astm.org.doi:10.1520/D7137_D7137M-12.

[18] M. Papila, Design of and with thin-ply non-crimp fabric (NCF) as building blocks for composites, Science and Engineering of Composite Materials (2016) 1-16doi:10.1515/secm-2015-0386.

[19] S. M. García-Rodríguez, J. Costa, V. Singery, I. Boada, J. A. Mayugo, The effect interleaving has on thin-ply non-crimp fabric laminate impact response: X-ray tomography investigation, Composites Part A: Applied Science and Manufacturing 107 (November 2017) (2018) 409-420. doi:10.1016/j. compositesa.2018.01.023.

[20] European standard DIN EN 2564:1998, Aerospace series, Carbon fibre laminates, Determination of the fibre-, resin- and void contents, Deutsches Institut für Normung (DIN), Berlin, Germany (1998). 
[21] A. Nettles, M. J. Douglas, A comparison of quasi-static indentation to low-velocity impact, NASA Technical Report, NASA/TP-2000-210481 (2000).

[22] A. Wagih, P. Maimí, N. Blanco, J. Costa, A quasi-static indentation test to elucidate the sequence of damage events in low velocity impacts on composite laminates, Composites Part A: Applied Science and Manufacturing 82 (2016) 180-189. doi:10.1016/j. compositesa.2015.11.041.

[23] E. Abisset, F. Daghia, X. Sun, M. Wisnom, S. Hallet, Interaction of inter- and intralaminar damage in scaled quasi-static indentation tests: Part 1 Experiments, Composite Structures 136 (2016) 712-726. doi:10.1016/j.compstruct. 2015.09.061.

[24] D. J. Bull, S. M. Spearing, I. Sinclair, Investigation of the response to low velocity impact and quasi-static indentation loading of particle-toughened carbon-fibre composite materials, Composites Part A: Applied Science and Manufacturing 74 (2015) 38-46. doi:10.1016/j.compositesa.2015.03.016.

[25] ASTM Standard D6641/D6641M-14, Standard Test Method for Compressive Properties of Polymer Matrix Composite Materials Using a Combined Loading Compression (CLC) Test Fixture. ASTM International, West Conshohocken, PA (2014). URL: www.astm.org.doi:10.1520/D6641_D6641M-16E01.

[26] M. Remacha, S. Sánchez-Sáez, B. López-Romano, E. Barbero, A new device for determining the compression after impact strength in thin laminates, Composite Structures 127 (2015) 99-107. doi:10.1016/j.compstruct.2015.02.079.

[27] M. Abir, T. Tay, M. Ridha, H. Lee, On the relationship between failure mechanism and compression after impact (CAI) strength in composites, Composite Structures 182 (15) (2017) 242-250. doi:10.1016/j.compstruct.2017.09.038. 
[28] D. Ghelli, G. Minak, Low velocity impact and compression after impact tests on thin carbon/epoxy laminates, Composites Part B: Engineering 42 (7) (2011) 2067-2079. doi:10.1016/j.compositesb.2011.04.017.

[29] N. O’Brien, R. Boardman, I. Sinclair, T. Blumensath, Recent advances in X-ray Cone-beam Computed Laminography, Journal of X-Ray Science and Technology 24 (5) (2016) 691-707. doi:10.3233/XST-160581.

[30] F. Léonard, J. Stein, C. Soutis, P. Withers, The quantification of impact damage distribution in composite laminates by analysis of X-ray computed tomograms, Composites Science and Technology 152 (2017) 139-148.

doi:10.1016/j.compscitech.2017.08.034.

[31] Starviewer Medical Imaging Software, URL: http://starviewer.udg.edu/.

[32] H. Choi, R. Downs, F. Chang, A New Approach toward Understanding Damage Mechanisms and Mechanics of Laminated Composites Due to Low-Velocity Impact: Part I-Experiments, Journal of Composite Materials 25 (1991) 992-1011. doi:10.1177/002199839102500803.

[33] I. Verpoest, S. Lomov, Virtual textile composites software WiseTex: Integration with micro-mechanical, permeability and structural analysis, Composites Science and Technology 65 (2005) 2563-2574. doi:10.1016/j.compscitech.2005.05.031.

[34] L. S. Sutherland, C. Soares, Impact characterisation of low fibre-volume glass reinforced polyester circular laminated plates, International Journal of Impact Engineering 31 (1) (2005) 1-23. doi:10.1016/j.ijimpeng.2003.11.006.

[35] S. Abrate, Impact on composite structures (1998). URL: www.cambridge.org/9780521473897.

[36] H. Choi, R. Downs, F. Chang, A New Approach toward Understanding Damage Mechanisms and Mechanics of Laminated Composites Due to Low-Velocity 
Impact: Part II-Analysis, Journal of Composite Materials 25 (1991) 1012-1038. doi:10.1177/002199839102500804.

[37] J. Nairn, Matrix Microcracking in Composites, Chapter 13 in Polymer Matrix Composites (edited by R. Talreja and J.-A. E. Månson), Comprehensive Composite Materials, Elsevier Science, Vol. 2, 2000, pp. 403-432.

[38] H. Saito, M. Morita, K. Kawabe, M. Kanesaki, H. Takeuchi, M. Tanaka, I. Kimpara, Effect of ply-thickness on impact damage morphology in CFRP laminates, Journal of Reinforced Plastics and Composites 30 (13) (2011) 1097-1106. doi:10.1177/0731684411416532. 


\section{List of Figures}

1 Load-displacement curves of representative LTHIN and LTHICK specimens impacted at a) $10 \mathrm{~J}$ and b) $14 \mathrm{~J}$. 1c-d: Load-displacement curves of indented and representative impacted LTHIN and LTHICK specimens (for visualization purposes, the part of LTHIN's impact curves that overlap with those of the quasi-static indentation test were suppressed). (For interpretation of the references to colour in this figure legend, the reader is referred to the web version of this article.) . . . . . . . . . . . .

2 Maximum load supported and energy dissipated by LTHIN and LTHICK specimens impacted at 10 and $14 \mathrm{~J}$ - horizontal lines refer to the average value between experiments, whereas vertical bars mean standard deviation.

$3 \quad$ C-scan projected damage area plotted against the energy applied during quasi-static indentation and impact events. In the impact data, horizontal lines refer to the average value between experiments, whereas vertical bars mean standard deviation. . . . . . . . . . . . . . . . . .

4 X-ray micro-computed tomography $(\mu \mathrm{CT})$ cross-sections of indented and representative impacted LTHIN specimens. The centre of impact is indicated with a cross. . . . . . . . . . . . . . . . .

$5 \mu \mathrm{CT}$ cross-sections of indented and representative impacted LTHICK specimens. The centre of impact is indicated with a cross, (i) is the delamination propagating at the first $0^{\circ} / 45^{\circ}$ interface below the midplane, (ii) is the tensile crack, (iii) are the shear cracks and (iv) are the "micro-cracks" developed along with delamination propagation [32, 36].

6 Projected damage area of indented LTHIN and LTHICK specimens obtained through post-process of the $\mu \mathrm{CT}$ slices, (iv) are the "micro-cracks" developed along with delamination propagation [32, 36]. (For interpretation of the references to colour in this figure legend, the reader is referred to the web version of this article.) . . . . . . . . . . . .

73 D damage scenario of a) LTHIN and b) LTHICK specimens indented at $\mathrm{d}=4 \mathrm{~mm}$. For visualization purposes, both images were extruded in the through-the-thickness direction and divided into 4 equally-thick sublaminates. (For interpretation of the references to colour in this figure legend, the reader is referred to the web version of this article.) . . . . . 3D damage scenario of a) LTHIN and b) LTHICK specimens indented at $\mathrm{d}=5.24 \mathrm{~mm}$. For visualization purposes, both images were extruded in the through-the-thickness direction and divided into 4 equally-thick sublaminates. 8c: Delamination migration favoured by a transverse crack developed within a resin pocket - the colour of the lines to the left of the picture refer to the interfaces highlighted in the legend. (For interpretation of the references to colour in this figure legend, the reader is referred to the web version of this article.) . . . . . . . . . . . 
9 Compressive strength of pristine and impacted LTHIN and LTHICK specimens. Horizontal lines refer to the average value between experiments, whereas vertical bars mean standard deviation. . . . . . . . .

A.1 1 pixel thick XZ orthogonal slices representing the damage developed in each ply/interface of the LTHICK specimen indented at $\mathrm{d}=3 \mathrm{~mm}$. Resin and carbon fibres appear in darker and lighter shades of grey, whereas matrix cracks/delaminations (originally in black) were segmented and coloured in red. In the sketch depicting the stacking sequence, the centre of impact is indicated with a cross. (For interpretation of the references to colour in this figure legend, the reader is referred to the web version of this article.) . . . . . . . . . . . . . . . . .

A.2 1 pixel thick XZ orthogonal slices representing the damage developed in each ply/interface of the LTHIN specimen indented at $\mathrm{d}=4 \mathrm{~mm}$. Resin and carbon fibres appear in darker and lighter shades of grey, whereas matrix cracks/delaminations (originally in black) were segmented and coloured in red. In the sketch depicting the stacking sequence, the centre of impact is indicated with a cross. (For interpretation of the references to colour in this figure legend, the reader is referred to the web version of this article.)

A.3 1 pixel thick XZ orthogonal slices representing the damage developed in each ply/interface of the LTHICK specimen indented at $\mathrm{d}=4 \mathrm{~mm}$. Resin and carbon fibres appear in darker and lighter shades of grey, whereas matrix cracks/delaminations (originally in black) were segmented and coloured in red. In the sketch depicting the stacking sequence, the centre of impact is indicated with a cross. (For interpretation of the references to colour in this figure legend, the reader is referred to the web version of this article.) . . . . . . . . . . . . . . 

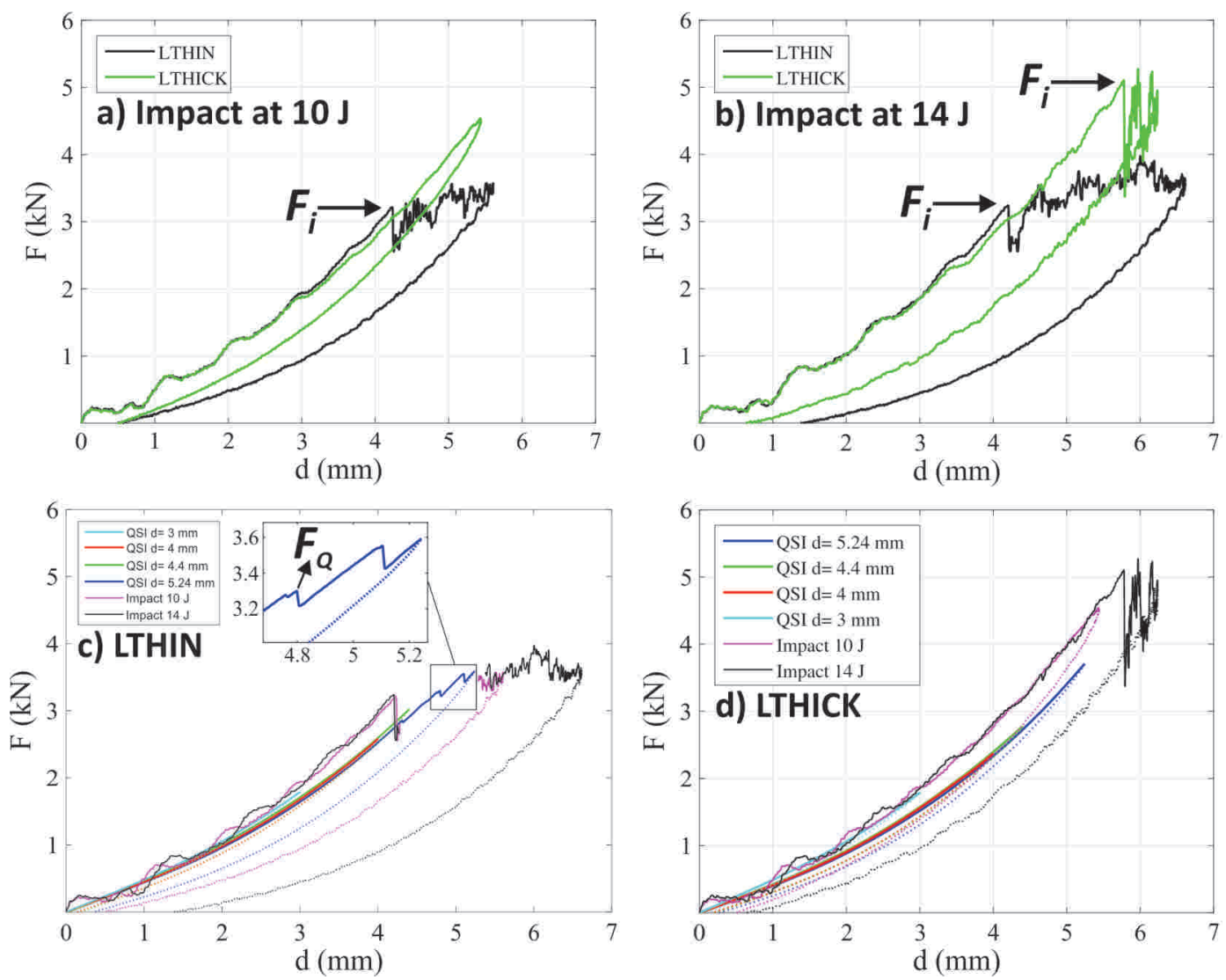

Figure 1: Load-displacement curves of representative LTHIN and LTHICK specimens impacted at a) $10 \mathrm{~J}$ and b) $14 \mathrm{~J} .1 \mathrm{c}-\mathrm{d}$ : Load-displacement curves of indented and representative impacted LTHIN and LTHICK specimens (for visualization purposes, the part of LTHIN's impact curves that overlap with those of the quasi-static indentation test were suppressed). (For interpretation of the references to colour in this figure legend, the reader is referred to the web version of this article.) 
FIGURES

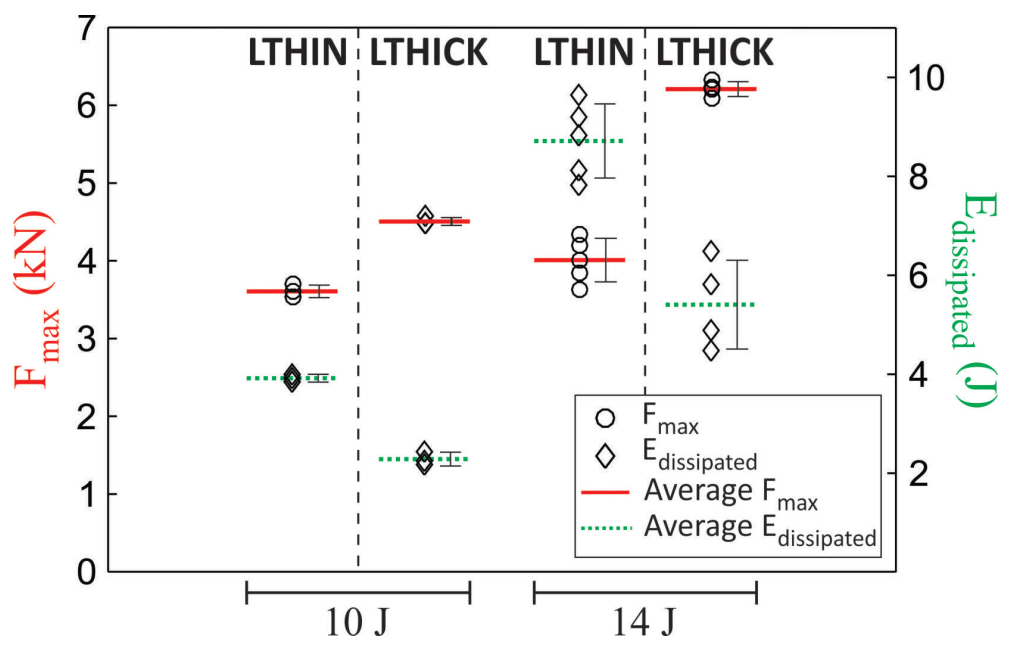

Figure 2: Maximum load supported and energy dissipated by LTHIN and LTHICK specimens impacted at 10 and $14 \mathrm{~J}$ - horizontal lines refer to the average value between experiments, whereas vertical bars mean standard deviation. 
FIGURES

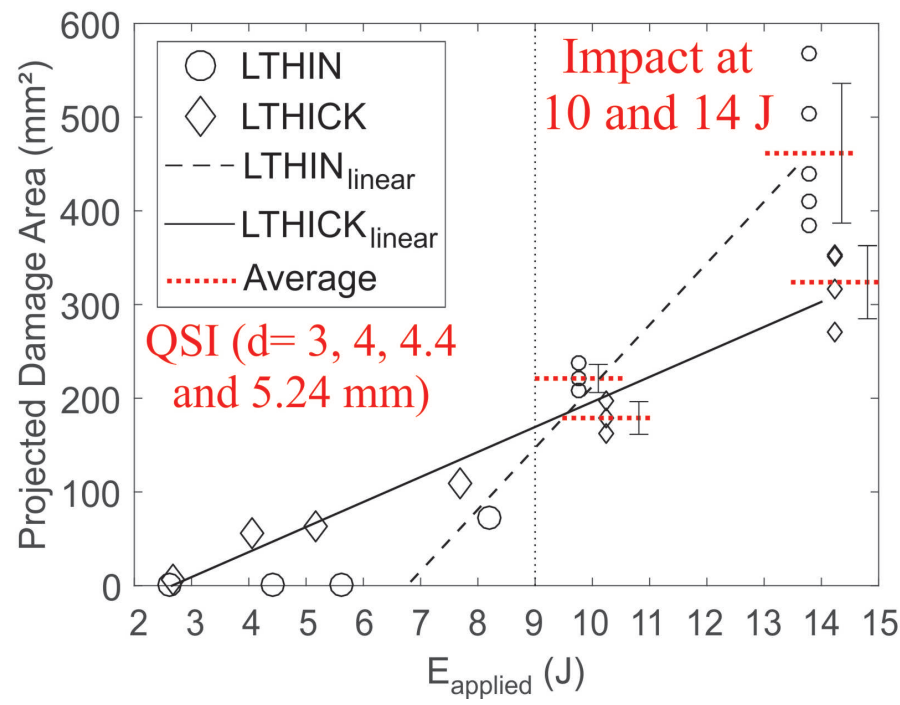

Figure 3: C-scan projected damage area plotted against the energy applied during quasi-static indentation and impact events. In the impact data, horizontal lines refer to the average value between experiments, whereas vertical bars mean standard deviation. 
FIGURES

\section{LTHIN}
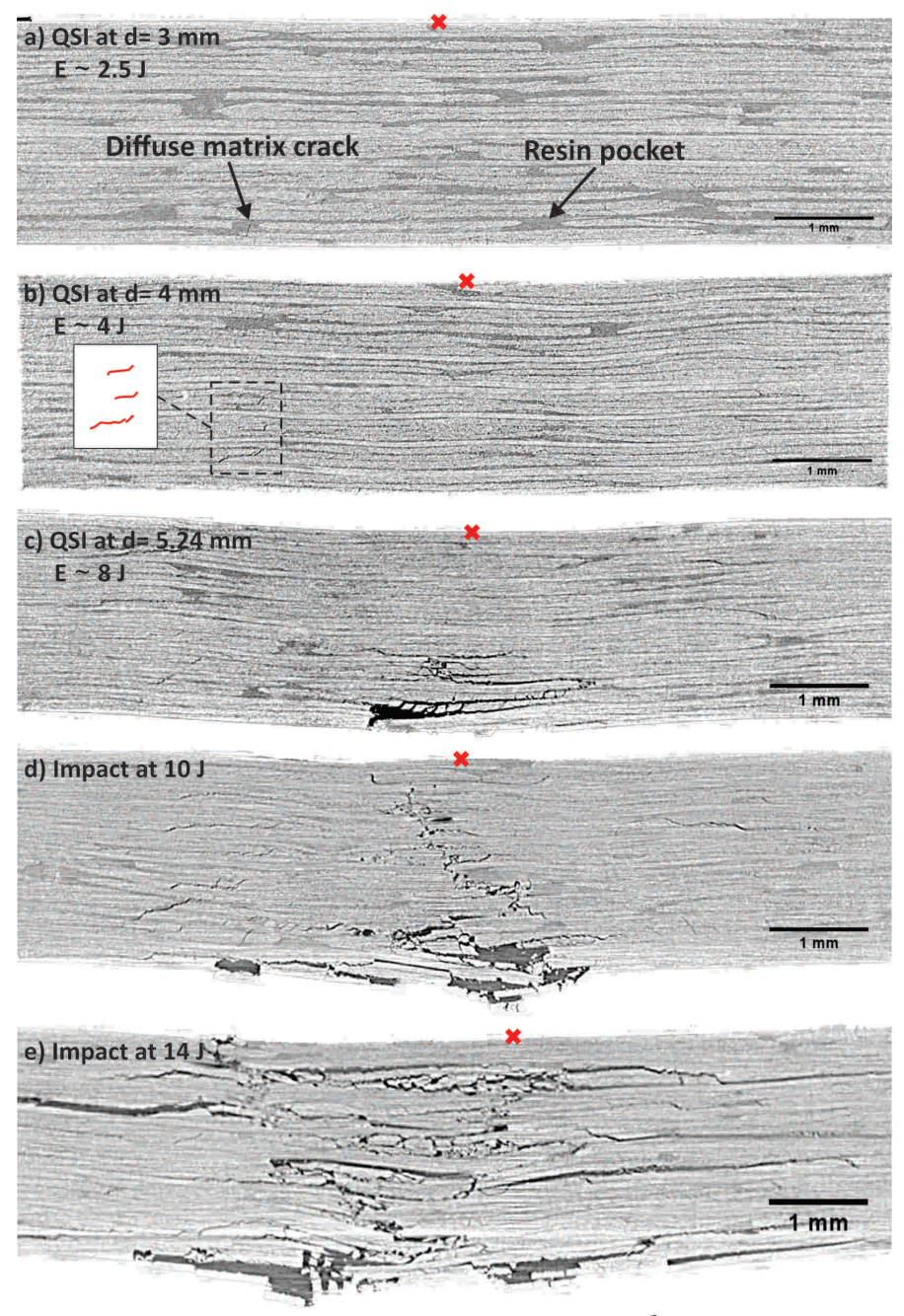

* Centre of impact
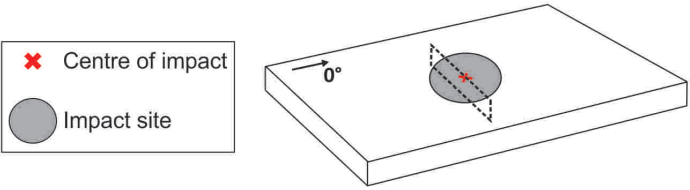

Figure 4: X-ray micro-computed tomography $(\mu \mathrm{CT})$ cross-sections of indented and representative impacted LTHIN specimens. The centre of impact is indicated with a cross. 
FIGURES

\section{LTHICK}
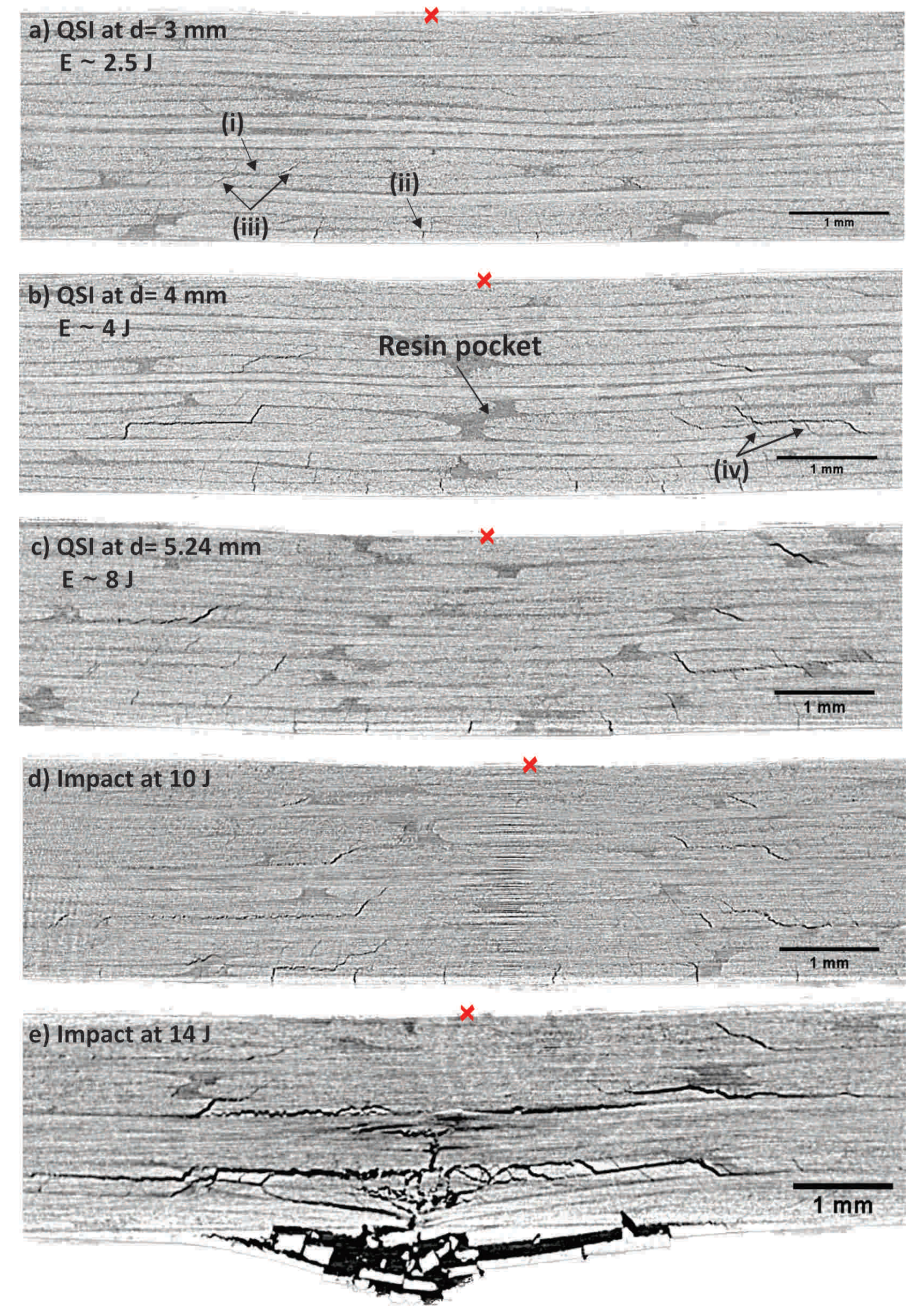

Figure 5: $\mu \mathrm{CT}$ cross-sections of indented and representative impacted LTHICK specimens. The centre of impact is indicated with a cross, (i) is the delamination propagating at the first $0^{\circ} / 45^{\circ}$ interface below the mid-plane, (ii) is the tensile crack, (iii) are the shear cracks and (iv) are the "micro-cracks" developed along with delamination propagation [32, 36]. 
FIGURES

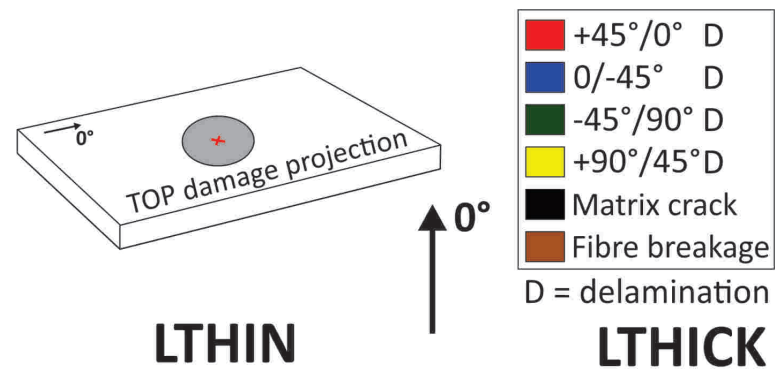

QSI at $\mathrm{d}=3 \mathrm{~mm}$

a)

\section{Non-damaged}

b)

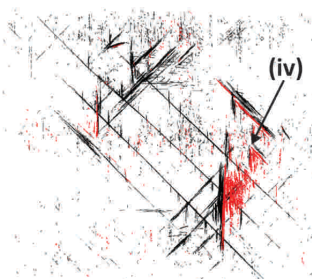

c)

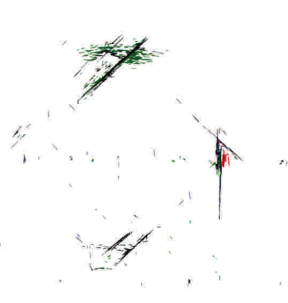

QSI at $\mathrm{d}=\mathbf{4} \mathrm{mm}$

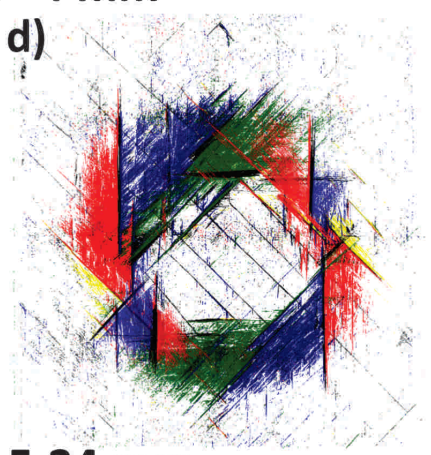

\section{QSI at $\mathrm{d}=5.24 \mathrm{~mm}$}

e)

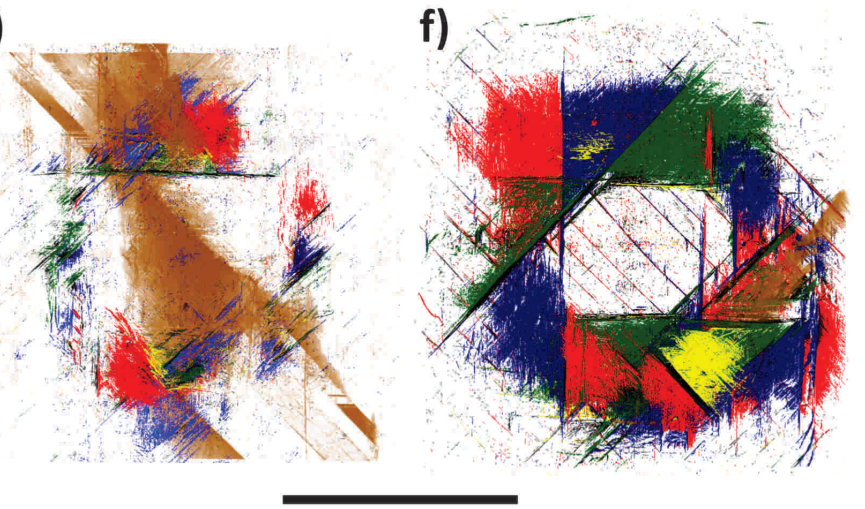

$6 \mathrm{~mm}$

Figure 6: Projected damage area of indented LTHIN and LTHICK specimens obtained through postprocess of the $\mu \mathrm{CT}$ slices, (iv) are the "micro-cracks" developed along with delamination propagation $[32,36]$. (For interpretation of the references to colour in this figure legend, the reader is referred to the web version of this article.) 
FIGURES

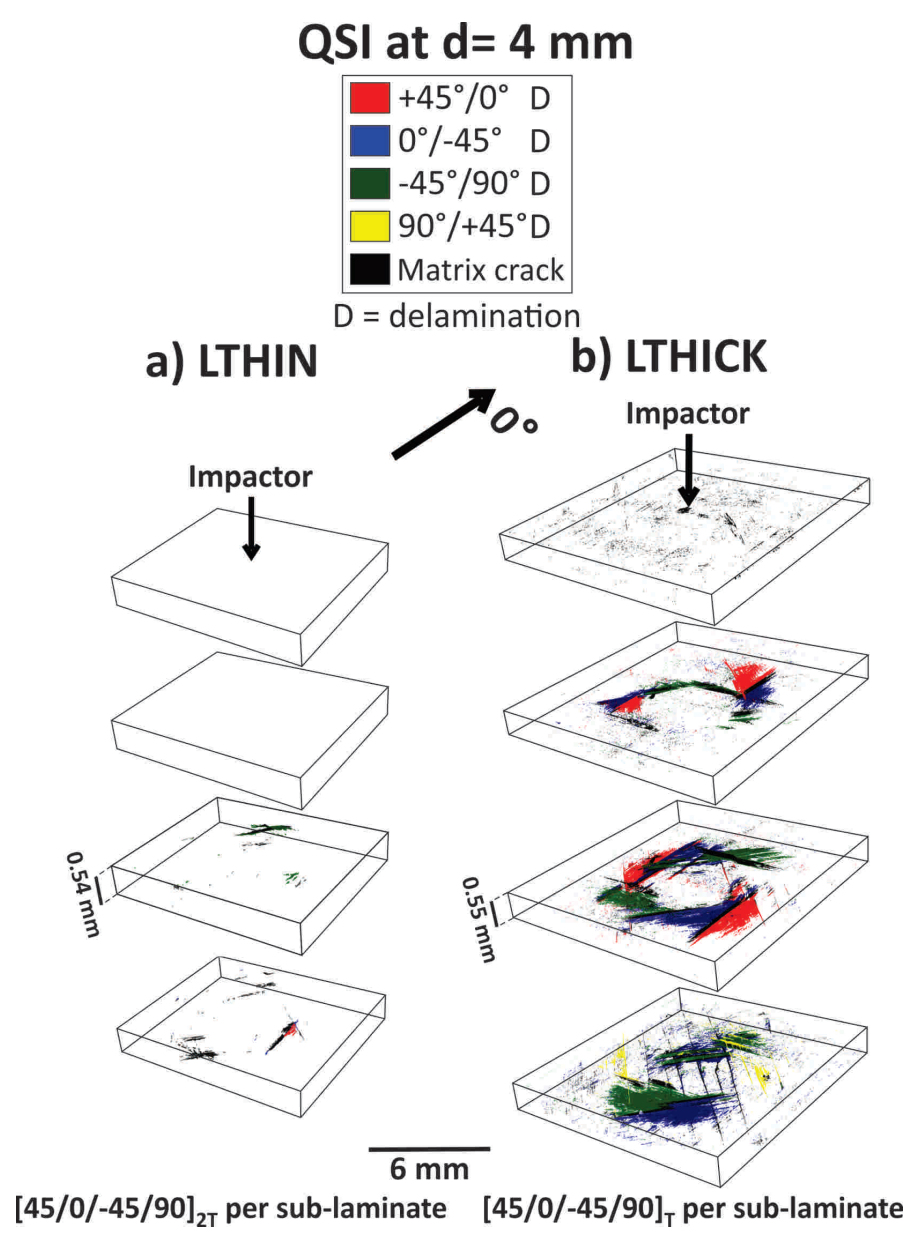

Figure 7: 3D damage scenario of a) LTHIN and b) LTHICK specimens indented at $\mathrm{d}=4 \mathrm{~mm}$. For visualization purposes, both images were extruded in the through-the-thickness direction and divided into 4 equally-thick sublaminates. (For interpretation of the references to colour in this figure legend, the reader is referred to the web version of this article.) 


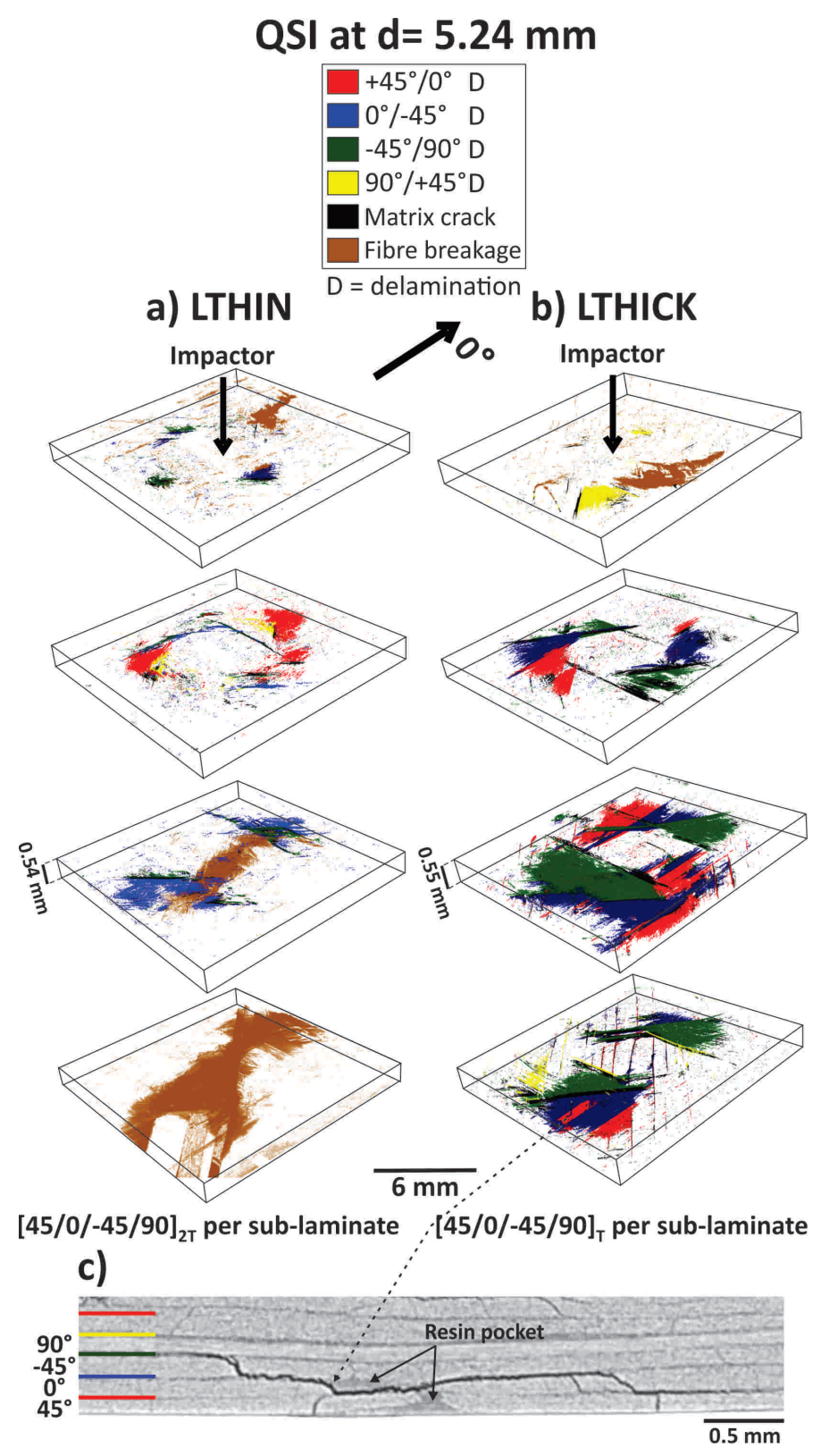

Figure 8: 3D damage scenario of a) LTHIN and b) LTHICK specimens indented at $\mathrm{d}=5.24 \mathrm{~mm}$. For visualization purposes, both images were extruded in the through-the-thickness direction and divided into 4 equally-thick sublaminates. 8c: Delamination migration favoured by a transverse crack developed within a resin pocket - the colour of the lines to the left of the picture refer to the interfaces highlighted in the legend. (For interpretation of the references to colour in this figure legend, the reader is referred to the web version of this article.) 


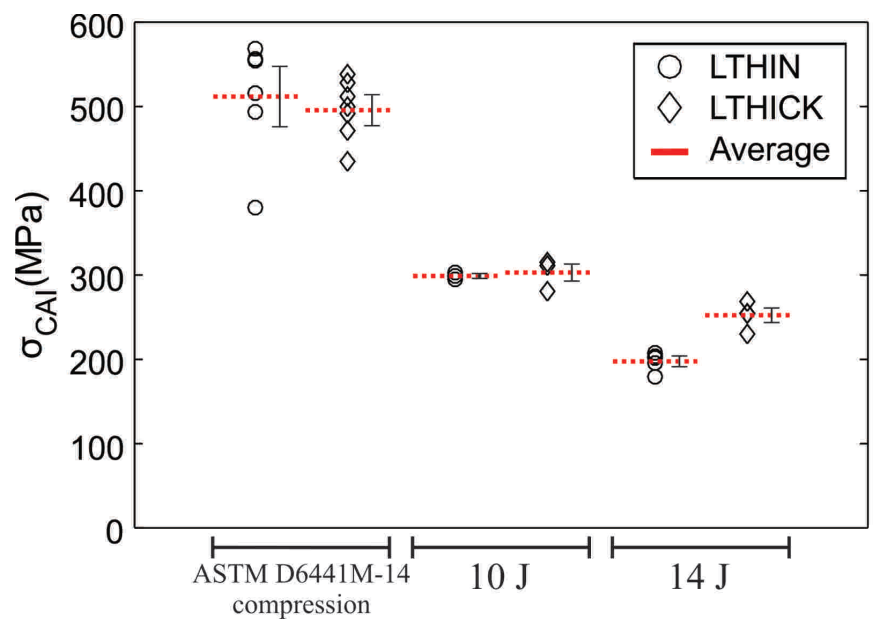

Figure 9: Compressive strength of pristine and impacted LTHIN and LTHICK specimens. Horizontal lines refer to the average value between experiments, whereas vertical bars mean standard deviation. 


\section{QSI of LTHICK at $\mathrm{d}=3 \mathrm{~mm}$}

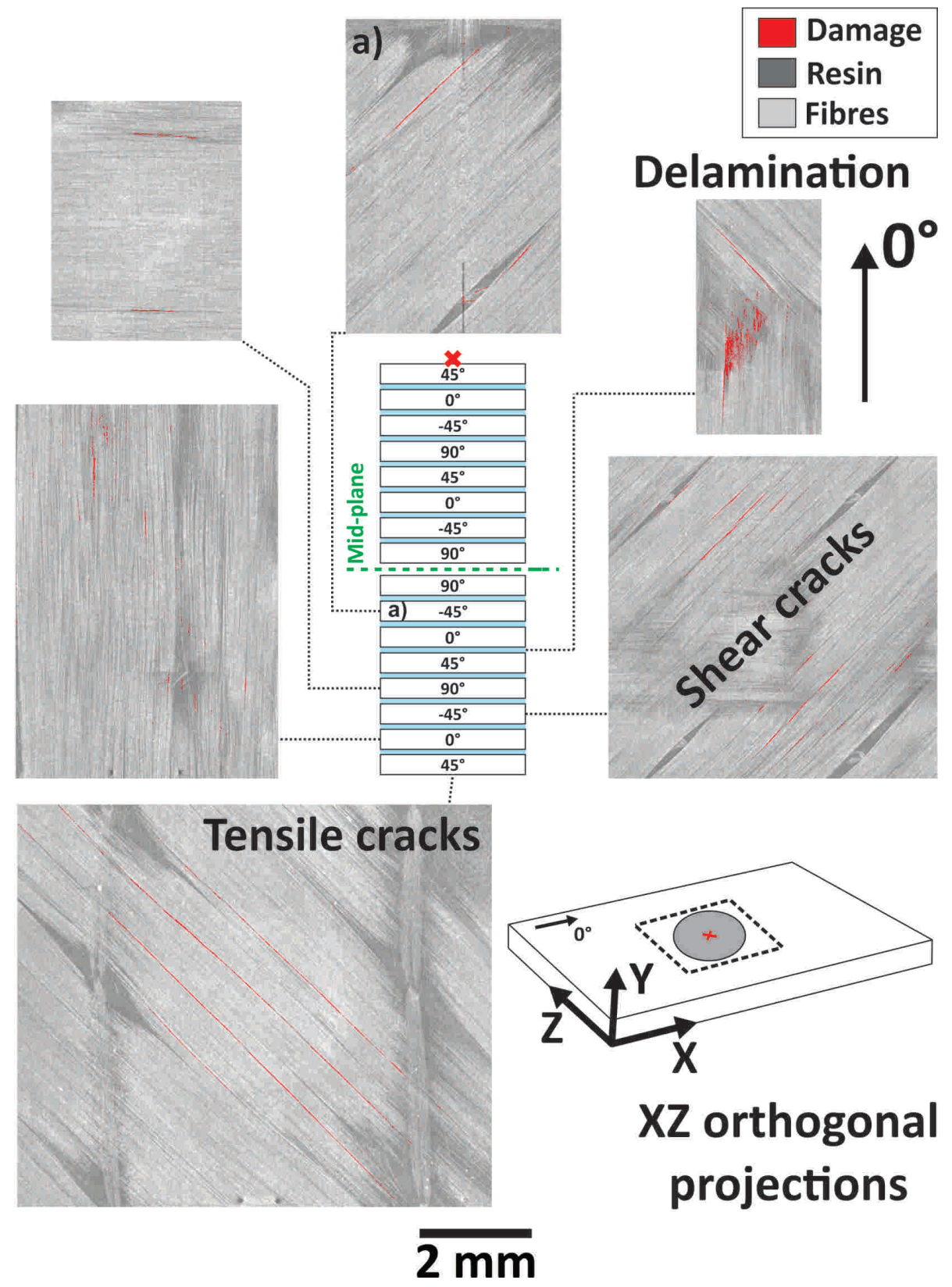

Figure A.1: 1 pixel thick XZ orthogonal slices representing the damage developed in each ply/interface of the LTHICK specimen indented at $\mathrm{d}=3 \mathrm{~mm}$. Resin and carbon fibres appear in darker and lighter shades of grey, whereas matrix cracks/delaminations (originally in black) were segmented and coloured in red. In the sketch depicting the stacking sequence, the centre of impact is indicated with a cross. (For interpretation of the references to colour in this figure legend, the reader is referred to the web version of this article.) 


\section{QSI of LTHIN at $\mathrm{d}=4 \mathrm{~mm}$}

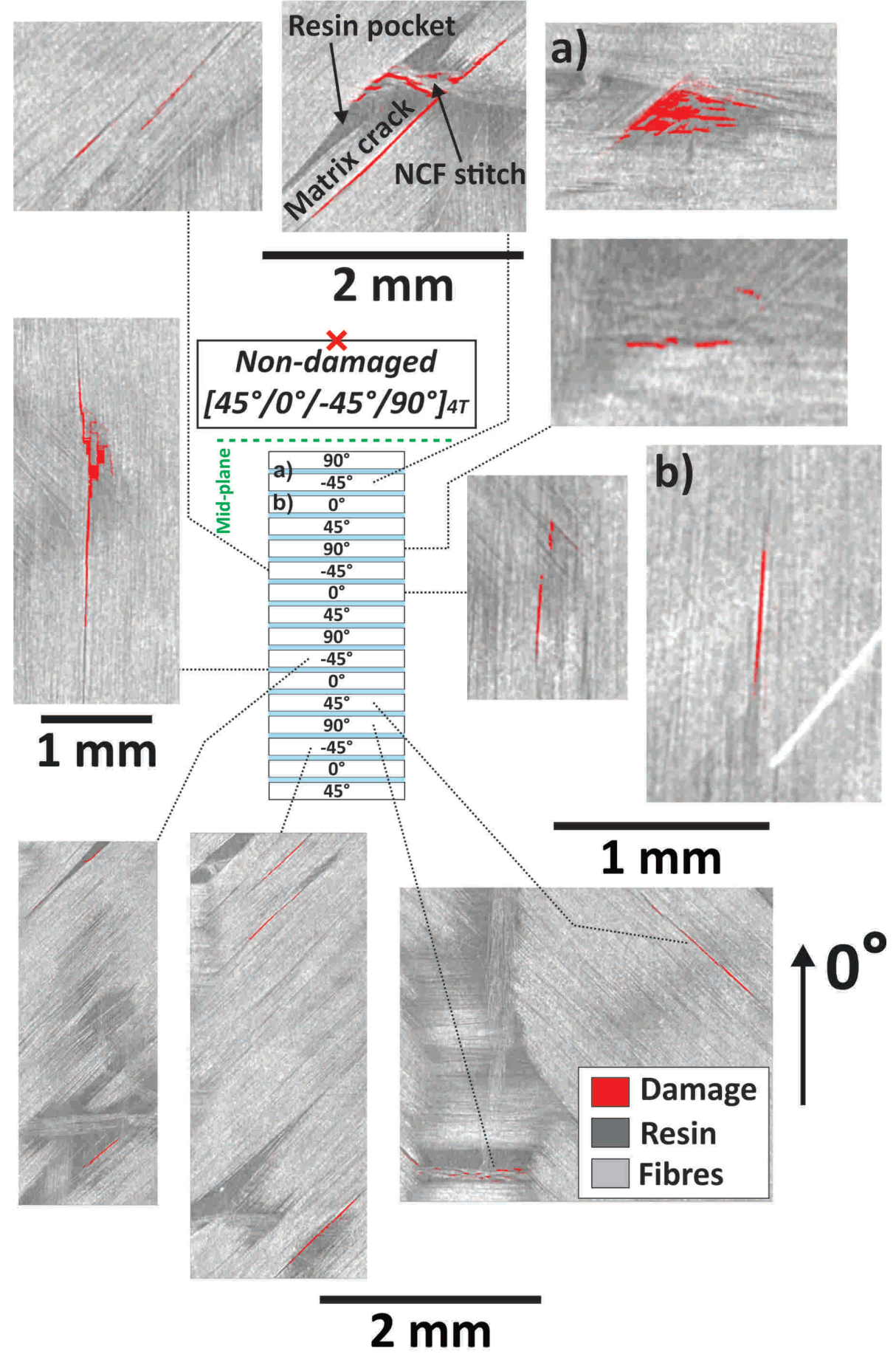

Figure A.2: 1 pixel thick XZ orthogonal slices representing the damage developed in each ply/interface of the LTHIN specimen indented at $\mathrm{d}=4 \mathrm{~mm}$. Resin and carbon fibres appear in darker and lighter shades of grey, whereas matrix cracks/delaminations (originally in black) were segmented and coloured in red. In the sketch depicting the stacking sequence, the centre of impact is indicated with a cross. (For interpretation of the references to colour in this figure legend, the reader is referred to the web version of this article.) 


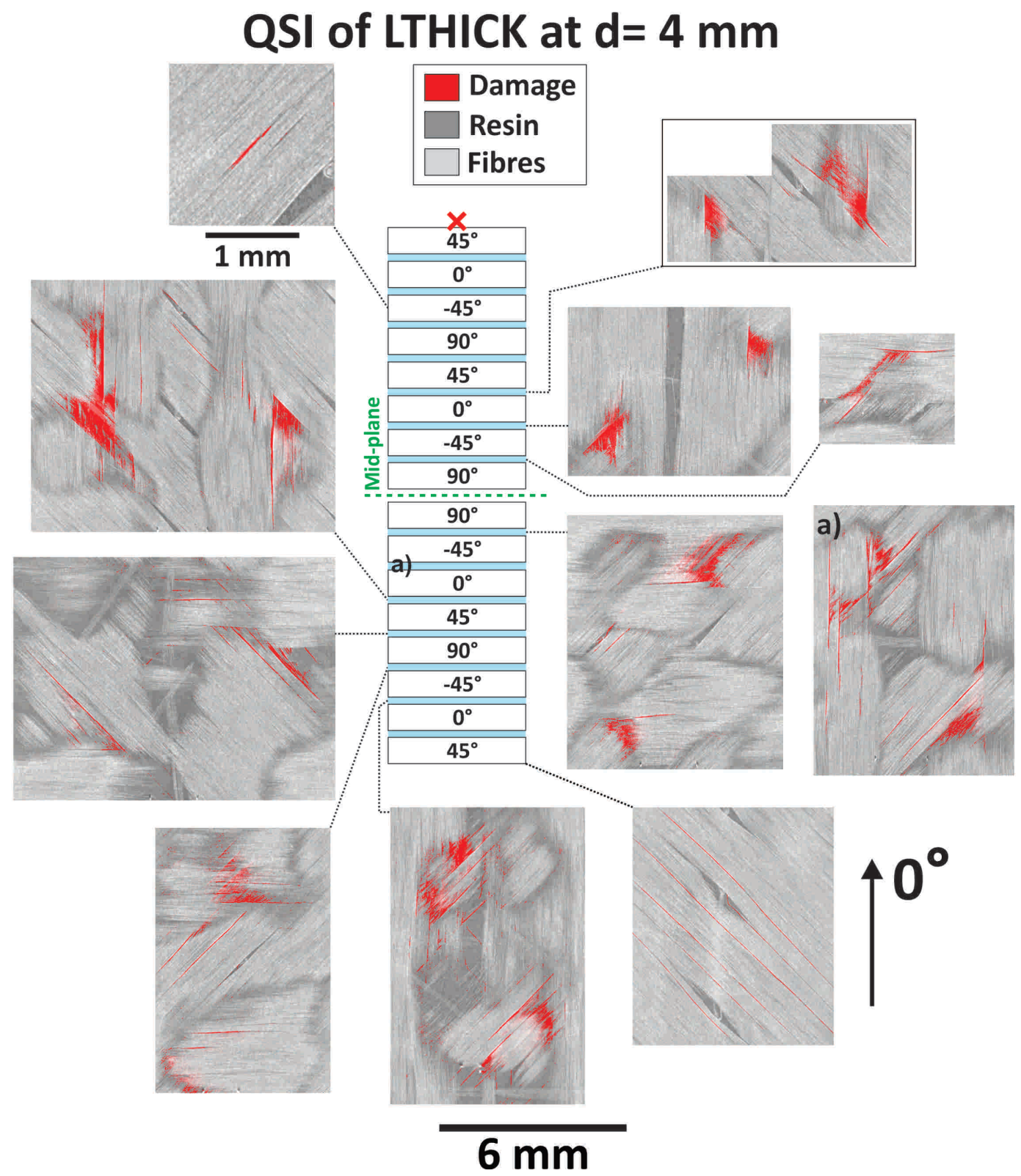

Figure A.3: 1 pixel thick XZ orthogonal slices representing the damage developed in each ply/interface of the LTHICK specimen indented at $\mathrm{d}=4 \mathrm{~mm}$. Resin and carbon fibres appear in darker and lighter shades of grey, whereas matrix cracks/delaminations (originally in black) were segmented and coloured in red. In the sketch depicting the stacking sequence, the centre of impact is indicated with a cross. (For interpretation of the references to colour in this figure legend, the reader is referred to the web version of this article.) 


\section{List of Tables}

1 Impact damage resistance and tolerance of carbon/epoxy prepreg thinply layups compared to their standard-ply counterparts. . . . . . . . .

2 Value of the local force maximum $\left(F_{i}\right)$ and magnitude of the associated load drop observed in the load-displacement curves of LTHIN and LTHICK specimens impacted at 10 and $14 \mathrm{~J}, \pm$ refers to the standard deviation between experiments. . . . . . . . . . . . 


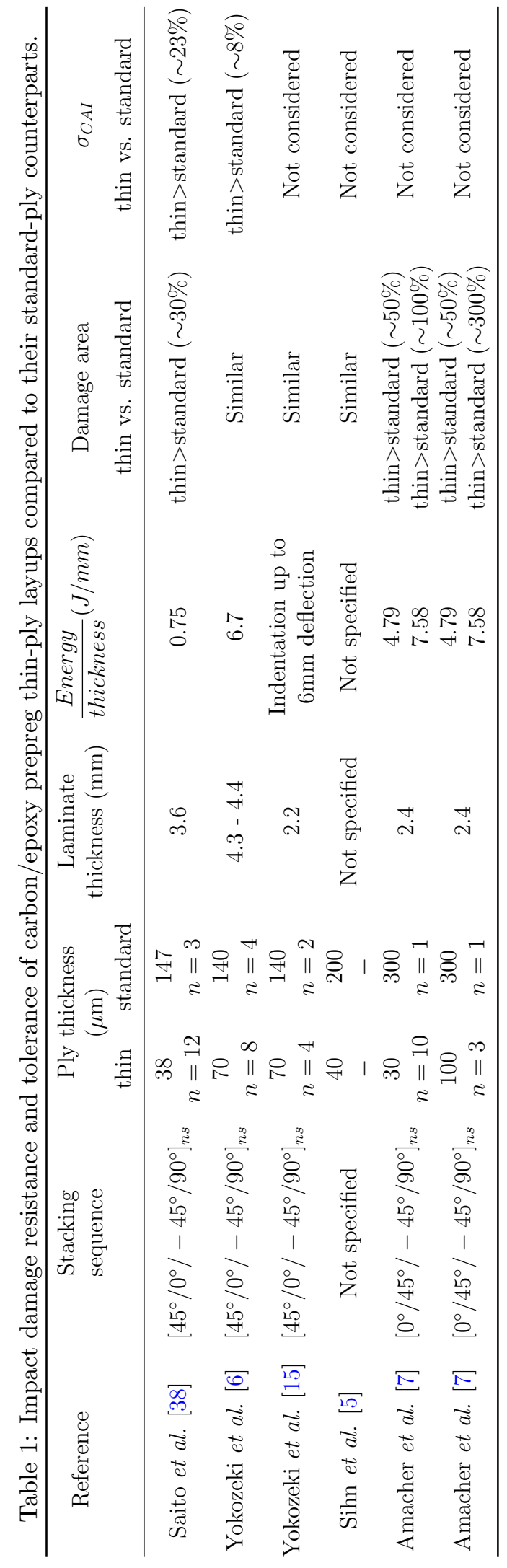




\section{TABLES}

Table 2: Value of the local force maximum $\left(F_{i}\right)$ and magnitude of the associated load drop observed in the load-displacement curves of LTHIN and LTHICK specimens impacted at 10 and $14 \mathrm{~J}, \pm$ refers to the standard deviation between experiments.

\begin{tabular}{|c|c|c|c|c|}
\hline \multirow[t]{2}{*}{ Material type } & \multicolumn{2}{|c|}{ Impact at $10 \mathrm{~J}$} & \multicolumn{2}{|c|}{ Impact at $14 \mathrm{~J}$} \\
\hline & $F_{i}(\mathrm{kN})$ & Load drop (\%) & $F_{i}(\mathrm{kN})$ & Load drop (\%) \\
\hline LTHIN & $3.24 \pm 0.02$ & $19.75 \pm 0.55$ & $3.41 \pm 0.25$ & $22.80 \pm$ \\
\hline LTHICK & None & None & $4.83 \pm 0.28$ & $20.63 \pm 8.21$ \\
\hline
\end{tabular}

